\title{
STUDY THERMAL BEHAVIOR OF HEAT CURE POLY (METHYL METHACRYLATE) REINFORCED BY BAMBOO AND RICE HUSK POWDERS FOR DENTURE APPLICATIONS
}

\author{
Jawad K. Oleiwi, \\ Material Engineering Department University of Technology, Baghdad, Iraq \\ E mail: jawadkad@yahoo.com \\ Qahtan Adnan Hamad, \\ Material Engineering Department University of Technology, Baghdad, Iraq. \\ Email:qah84@yahoo.com \\ Hadil Jabbar Abdul Rahman, \\ E mail: hadil.jabbar.85@gmail.com \\ Material Engineering Department University of Technology, Baghdad, Iraq.
}

\begin{abstract}
The present research, studies the effect of adding two different types of reinforcing powders, which included: Bamboo (Ba) and Rice Husk $(\mathrm{RH})$, that added with different weight fractions (2, 4, 6 and 8 wt. \%), and with the selected size particles of $(25 \mu \mathrm{m}$ and $75 \mu \mathrm{m})$ on thermal behavior of heat Cure Poly (Methyl Methacrylate) such as thermal conductivity and thermal diffusivity in addition to the differential scanning calorimetry (DSC) analysis and these tests were accomplished at temperature of laboratory. The poly Methyl Methacrylate properties which reinforced by (Bamboo and Rice Husk) powders are mainly influenced by the interfacial adhesion strength between the powders and the matrix, and in order to get better correlation between the natural powder and PMMA matrix, so the powders were treated with alkali (sodium hydroxide $\mathrm{NaOH}$ ) solution prior to use as reinforcement materials. The results showed that the values of the thermal conductivity and thermal diffusivity increased with increasing of the weight fraction for both particle sizes $(25 \mu \mathrm{m}$ and $75 \mu \mathrm{m})$ of natural powders.
\end{abstract}

Keywords: Acrylic Resin, Natural powders, Bamboo, Rice Husk, Denture

\section{INTRODUCTION}

Science of dental materials is the study of the chemical composition and properties of fabricated and designed materials that are used dentistry field and the manner in which they interact with the environment they are placed in. The most important characteristics of dental material are being biocompatible, non-toxic, non-irritating, non-allergenic, mechanical resistant to fracture, does not deteriorate over time, dimensionally stable, miner change by temperature and solvents. These characteristics vary according to types of dental materials to be used for their intended purpose [1]. Poly (methyl methacrylate) properties are modified when reinforced by adding many particles or fibers, this is approach the scientist to study the effected of reinforced materials on the mechanical and physical properties for the composite material. The glass transition temperature $\left(T_{g}\right)$ of commercial poly methyl 
methacrylate (PMMA) it ranges from $\left(65\right.$ to $\left.165{ }^{\circ} \mathrm{C}\right)$ [2 and 3]. The literature surveys include some researches, which are accomplished in this field, it's:

Q.A. Hamad, [4] studied the effect of adding two various types of reinforcing powders, which inclusive: nano-alumina (nano- $\mathrm{Al}_{2} \mathrm{O}_{3}$ ) and nanosilica (nano $\mathrm{SiO}_{2}$ ), on some physical properties of composite prosthesis complete denture base materials. The result showed the values of (thermal conductivity and thermal diffusivity) properties raised with increasing the volume fraction of both (nano- $\mathrm{Al}_{2} \mathrm{O}_{3}$ and nano$\mathrm{SiO}_{2}$ ) powders in PMMA complete denture base materials.

S.I. Salih et. al., [5] investigated the prorated study the properties of flexural and the strength impact for PMMA prosthetic complete denture base reinforced by different particles. The result showed the flexural properties rise with increasing the volume fraction of the while, reduced the impact strength. The one recent study mentioned elsewhere, which involved the numerical study by the tensile properties analysis of the prosthetic dentures which prepared from the same of composite material maintained in the reference above.

Jawad, K. Olewi et. al. [6] studied the effects of the particles size and volume fraction of silica $\mathrm{SiO}_{2}$ ceramic particles on the mechanical characteristics of PMMA polymer. The results showed that the maximum shear stress, bending modulus, tensile strength, elongation percentage and modulus elasticity of PMMA composites are increased with increasing the addition of $\mathrm{SiO}_{2}$ particles and with the increase in the volume fraction of $\mathrm{SiO}_{2}$ particles.

Azlan et. al. [7] investigated the effects of adding the hydroxyapatite (HA) with different volume fraction $(5 \%, 10 \%, 15 \%, 20 \%)$, on the toughness of fracture, flexural and thermal properties of heat cure PMMA resin to form PMMA/HA composites. The results showed the flexural modulus and thermal conductivity of PMMA was increased by increasing the volume fraction of HA particles this is referred to the reinforcement influences of $\mathrm{HA}$ particles.

For Ayman E. et. al., [8] this study investigates the effect of adding the aluminum $\left(\mathrm{Al}_{2} \mathrm{O}_{3}\right)$ particles with different weight fraction $(5 \%, 10 \%, 15 \%$, and $20 \%)$, on the flexural strength and thermal diffusivity of heat-polymerized acrylic resin. It was found increased significantly the flexural strength and thermal diffusivity in attribution to the percentage weight of alumina $\left(\mathrm{Al}_{2} \mathrm{O}_{3}\right)$ particles.

According to Schajpal S. B. et. al. [9] this study investigates the effect of adding the (silver, copper and aluminum) powders to acrylic denture base resin in different volume fraction. They found when increased, all these types of metal fillers lead to increased compressive strength, but decrease in tensile strength, also the fillers increased thermal conductivity but did not proportionally as the filler concentration increased. 


\section{MATERIALS AND METHODS THE MATERIAL WHICH USED IN THIS STUDY}

The DURACRYL PLUS heat-curing base resin, fabricated by Spofa Dental Company used as a matrix in this research. Rice Husk and bamboo powders in two different particles sizes (25 \& $75 \mu \mathrm{m})$ and four weight fraction $(2,4,6 \& 8 \%)$ used as reinforcing materials in acrylic resin. Figure (1) illustrates the methyl methacrylate powder and monomer and the Rice Husk, Bamboo powders which used to manufacture composite specimens.

The rice husk and bamboo were washed many time then treated with $(\mathrm{NaOH})$ to remove lignin, pectin, waxy substances, and natural oils covering the external surface of the material cell wall and dried for five days then grinding and milling by grinder to very small particles then sieving to separate the various particle size.

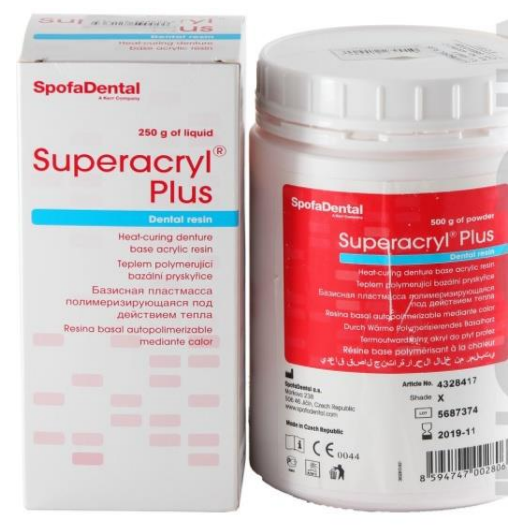

(a)

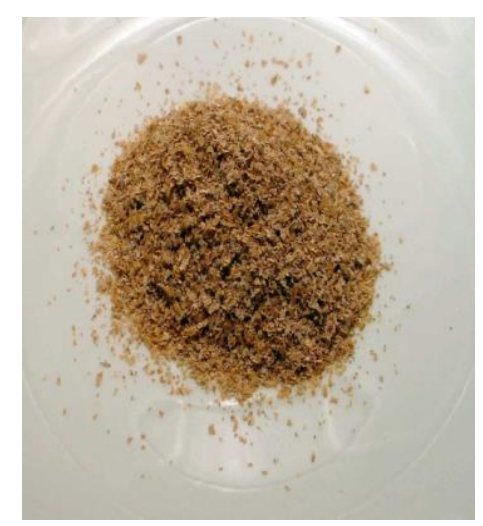

(b)

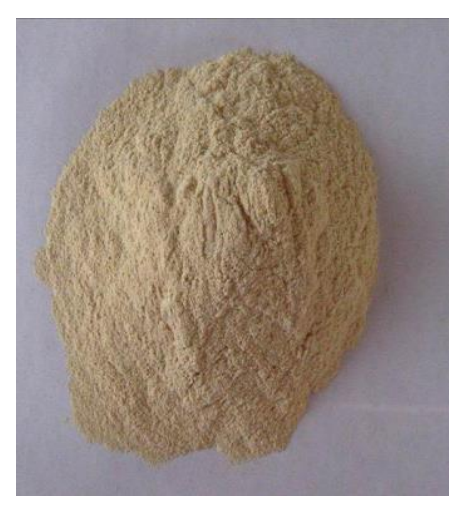

Figure (1): (a) The powder and monomer of methyl methacrylate

(b) Rice Husk powder.

(c) Bamboo powder. 
AL-QADISIYAH JOURNAL FOR ENGINEERING SCIENCES
Vol.11, No.4

ISSN: $1998-4456$

Table (1): Some properties of PMMA [10].

\begin{tabular}{|c|c|}
\hline Properties & values \\
\hline Coefficient of thermal expansion & $81-162\left(10^{-6}\left(\mathrm{c}^{\circ}\right)^{\wedge}-1\right)$ \\
\hline Thermal conductivity & $\begin{array}{c}0.37 \mathrm{~m} \mathrm{cal} / \mathrm{s}\left(\mathrm{cm}^{2}\right)\left(\mathrm{c}^{\circ} / \mathrm{cm}\right)= \\
(0.17-0.25) \mathrm{W} / \mathrm{m} . \mathrm{k})\end{array}$ \\
\hline Thermal diffusivity & $(0.123-0.125)\left(\mathrm{mm}^{2} / \mathrm{s}\right)$ \\
\hline Density & $(1.1 .7-1.2)\left(\mathrm{gm} / \mathrm{cm}^{3}\right)$ \\
\hline
\end{tabular}

The resin is mixed in the weight rate 2.25:1 (two and a half parts of powder, one part of liquid), the mould which is closed put inside curing instrument for around (30 min.) a temperature equal to around $\left(70^{\circ} \mathrm{C}\right)$ and pressure equal to around (2.5 bar) according to company instructions to perform the curing process and in order to accomplished polymerization process of acrylic specimens and to improve physical properties. And then raise the temperature for around (30 $\mathrm{min})$ to the $\left(100{ }^{\circ} \mathrm{C}\right.$ ) and stay at this temperature for one hour. Then the process of cooling the mould begins inside the curing device in order to remove the residual monomer.

The powders are treated with solution of $5 \%$ sodium hydroxide at $25^{\circ} \mathrm{C}$ for one day, keeping a powderto-liquor ratio of 1:30 weight to volume and then washed the treated powders many times by using distilled water to eject overflow alkali sticking on their surface, then the distilled water which was neutralized (PH-7) a few drops of acetic acid Put it in and washed with distilled water again, then the treated powders stayed for 5 days to dry at room temperature and finally kept in a hot air furnace at $\left(50-60^{\circ} \mathrm{C}\right)$. The process of mixing between the monomer liquid (MMA) with reinforcement particles (Bamboo or Rice Husk) should be homogeneous and constantly.

Then added the powder to the mixture and mixed progressively. The samples of acrylic resin were de-molded to eject from the mould holes which has upper and lower surface very smooth, and to remove the stress which residual followed by heat treatment at $100^{\circ} \mathrm{C}$ for $2 \mathrm{~h}$.

\section{RESULTS AND DISCUSSION}

\subsection{PAGE THERMAL CONDUCTIVITY RESULTS}

Figures ( $2 \& 3$ ) illustrate the effects of the thermal conductivity on weight fraction of (Bamboo and Rice Husk) powders respectively at both particles size $(25 \mu \mathrm{m}$ and $75 \mu \mathrm{m})$ in PMMA resin. The values of the thermal conductivity increased with rise of the weight fraction for both particles size of natural powders. This due to the fact of natural these powders which have high thermal conductivity value compared with the PMMA matrix [11]. 


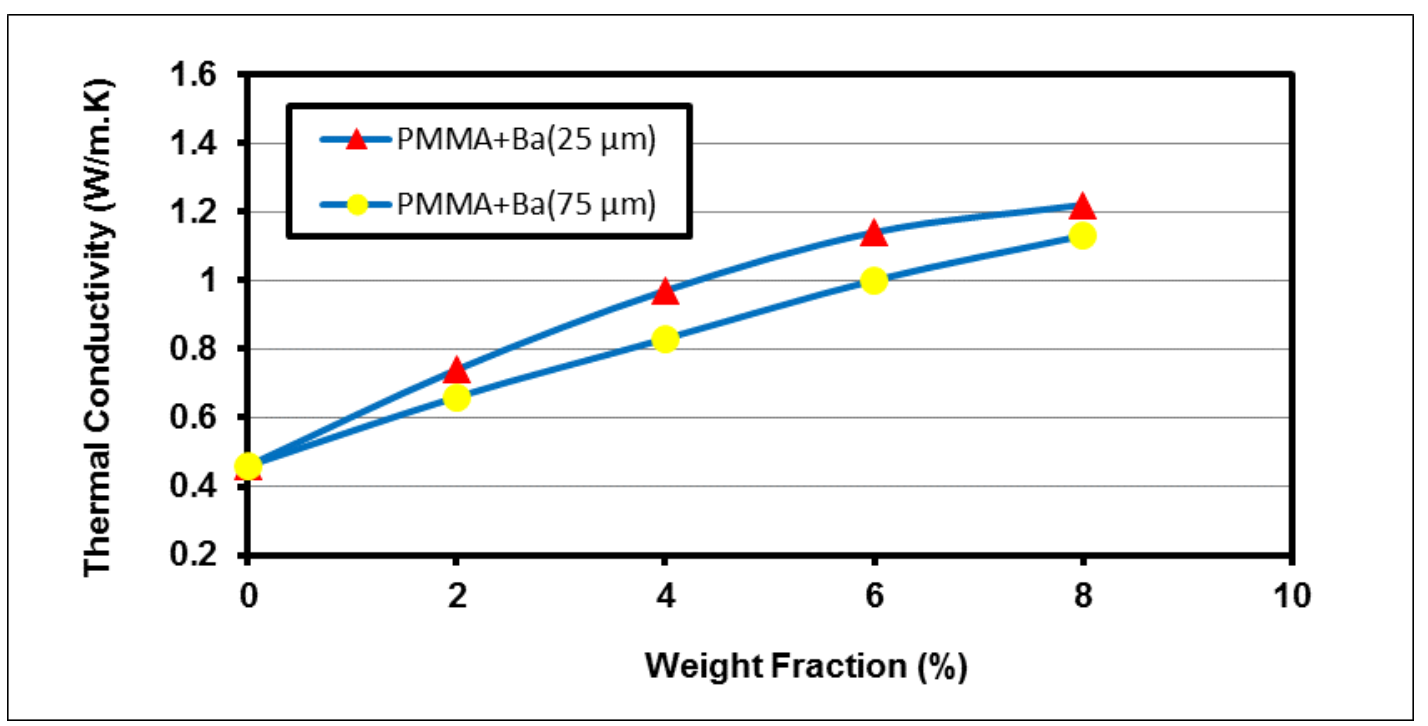

Figure (2): Thermal Conductivity and Weight Fraction of Bamboo Powder at both Particles Sizes for PMMA Composite Specimens.

In addition, the presence of these particles is made to fill or diminish all spaces and voids which were inside the PMMA matrix. Finally, these reasons lead to facilitate the process of the heat transfer through composite specimens. So, the presence of the powders can considerably improve the thermal conductivity [2 and 3$]$.

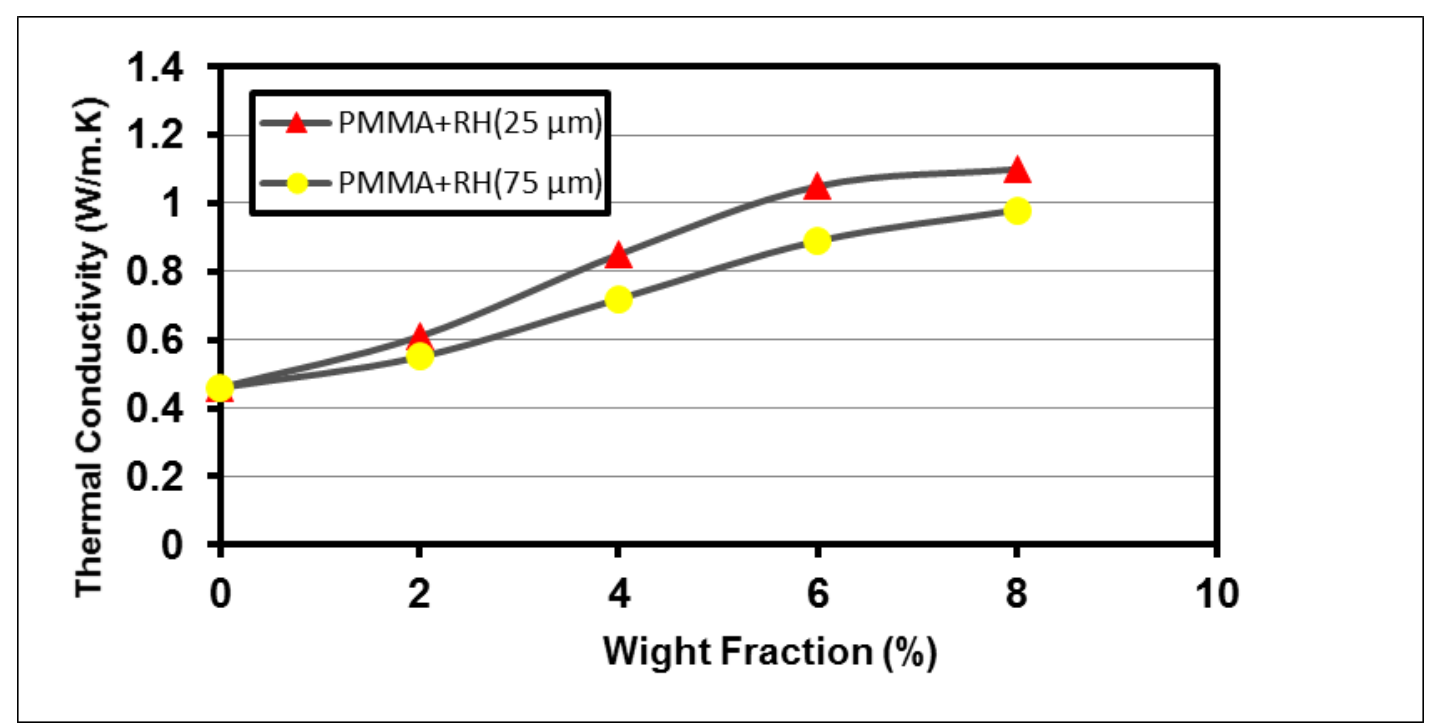

Figure (3): Thermal Conductivity and Weight Fraction of Rice Husk Powder at both Particles Sizes for PMMA Composite Specimens. 


\section{AL-QADISIYAH JOURNAL FOR ENGINEERING SCIENCES}

Vol.11, No.4

ISSN: $1998-4456$

Thus, the thermal conductivity values increase from $(0.46 \mathrm{~W} / \mathrm{m}$. K) for PMMA to $(1.22 \mathrm{~W} / \mathrm{m}$. K) for (PMMA - 8\% Ba) composite specimen at particle size $(25 \mu \mathrm{m})$ and to $(1.1 \mathrm{~W} / \mathrm{m}$. K) for (PMMA - $8 \%$ $\mathrm{RH})$ composite specimen at particle size $(25 \mu \mathrm{m})$.

\subsection{THERMAL DIFFUSIVITY RESULTS}

The Figures (4 and 5) illustrates the dependence of the thermal diffusivity on weight fraction of (Bamboo and Rice Husk) powders respectively at both particles size (25 $\mu \mathrm{m}$ and $75 \mu \mathrm{m})$ in PMMA resin. It can be shows that the values of the thermal diffusivity increased with increasing of the weight fraction for both particles size of both powders. It can also be noticed that the thermal diffusivity of PMMA composite that content Bamboo powder or Rice Husk powder at particles size $(25 \mu \mathrm{m})$ is higher than the thermal diffusivity at particles size $(75 \mu \mathrm{m})$. Thus, the thermal diffusivity value increased from $\left(0.3 \mathrm{~mm}^{2} / \mathrm{s}\right)$ for PMMA to $\left(1.04 \mathrm{~mm}^{2} / \mathrm{s}\right)$ for (PMMA - 8\% Ba) composite specimen at particles size $(25 \mu \mathrm{m})$ and to $\left(0.953 \mathrm{~mm}^{2} / \mathrm{s}\right)$ for (PMMA - 8\% RH) composite specimen at particles size $(25 \mu \mathrm{m})$.

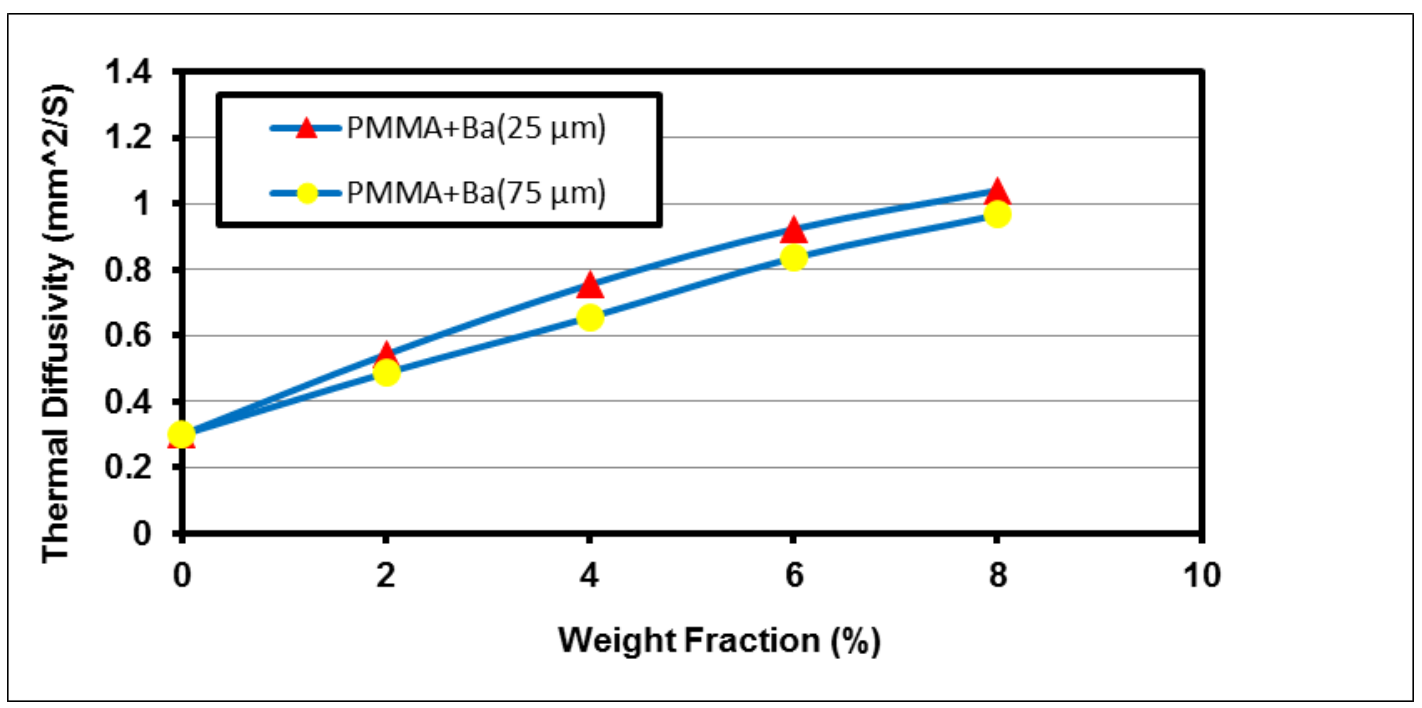

Figure (4): The Relationship between Thermal Diffusivity and Weight Fraction of Bamboo Powder at both Particles Sizes for PMMA Composite Specimens. 

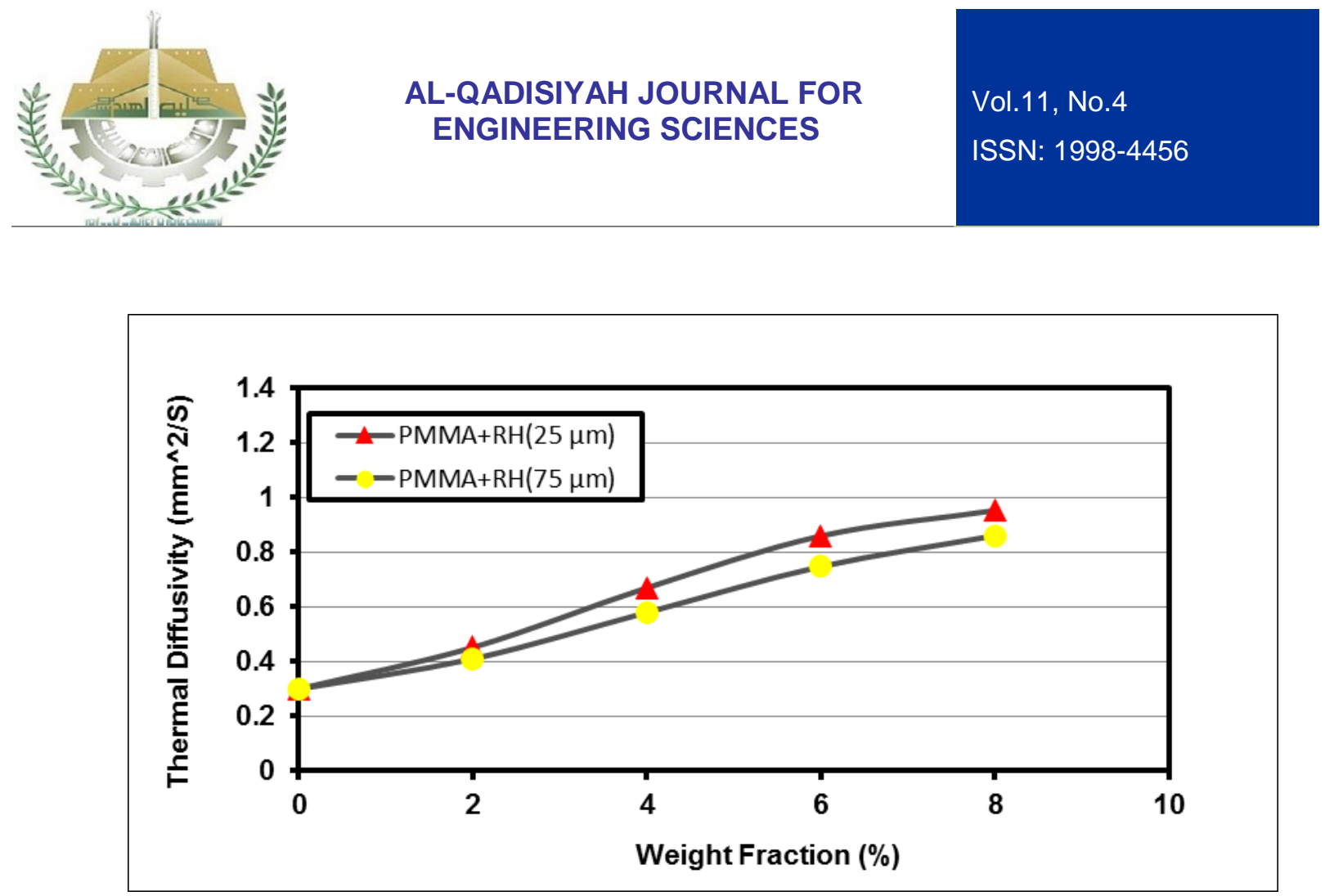

Figure (5): The relationship between thermal diffusivity and Weight Fraction of at Rice Husk both particles sizes for PMMA Composite Specimens.

Also, the addition of both types of powders at both particles size leads to a significant increase in the value of the thermal diffusivity in comparison with the pure PMMA. Also the highest value of thermal diffusivity was obtained in composite material when adding Bamboo powder at particles size $(25 \mu \mathrm{m})$.

\section{DIFFERENTIAL SCANNING CALORIMETRIC TRACES DSC TEST}

The most important thermal properties in this test are glass transition temperature $\left(T_{g}\right)$.

The values of glass transition temperature, melting temperature and crystallization temperature for PMMA material specimens before and after adding both types of natural powders (Bamboo or Rice Husk powders) for both particles size at weight fraction (8\%) are listed in Table (2).

It was observed from the Table (1) that the PMMA composites varies for many reasons including, changes in nature and type of reinforcing material in composite and the particle size of natural powder in composites.

However, the DSC scans of PMMA composite specimens with presence both types of natural powders (Bamboo and Rice Husk) at both particle size in the PMMA matrix, leads to the increases of $\left(T_{g}\right)$, due to the good interfacial reaction between reinforcing materials and PMMA polymer in composites, that produced strong bonding between reinforcing materials and PMMA polymer composite. Also observed the nature of natural powders (Bamboo and Rice Husk), which did to restricted the PMMA chain mobility, and acted as an agent to increase the cross-linking density between themselves and PMMA chains. Finally, that leads to increases in the molten state viscosity and rise the glass transition temperature for all composite specimens, these results are consistent with previous results as reported in the sources [14 and 15].

The maximum value of glass transition temperature was obtained in the composite specimen (PMMA - $8 \%$ $\mathrm{Ba}$ ) at particle size $(25 \mu \mathrm{m})$. It can be also noticed that the composite specimen (PMMA-8 \% $\mathrm{Ba}$ ) having a higher value of glass transition temperature than composite specimen (PMMA-8 \% RH) at both particle size. Furthermore, the study of DSC thermal analysis indicated that there is no significant change in the heat flow behavior between the pure PMMA and PMMA composites materials, as well as it indicates to effective compatibility between constituents of PMMA composite. 


\section{AL-QADISIYAH JOURNAL FOR ENGINEERING SCIENCES}

Vol.11, No.4

ISSN: $1998-4456$

In addition, it can be noticed from Table (2), there is not any significant can be mentioned about the effect of adding Bamboo powder and Rice Husk powder on the other properties values (melting temperature and crystallization temperature) for PMMA pure and composite PMMA specimens

Table (2): The Important Characterization of DSC Curves for PMMA pure and composite PMMA Specimens for Denture Base Materials.

\begin{tabular}{|l|l|l|l|}
\hline Specimen & $\mathbf{T}_{\mathbf{g}}\left({ }^{\circ} \mathrm{C}\right)$ & $\mathbf{T}_{\mathbf{c}}\left({ }^{\circ} \mathrm{C}\right)$ & $\mathbf{T}_{\mathbf{m}}\left({ }^{\circ} \mathrm{C}\right)$ \\
\hline Pure PMMA & 121.5 & 356.7 & 412.152 \\
\hline PMMA - 8 \% Ba at $(75 \mu \mathrm{m})$ & 129.1 & 394.7 & 540.98 \\
\hline PMMA - 8 \% Ba at $(25 \mu \mathrm{m})$ & 131.6 & 383.8 & 431.369 \\
\hline PMMA - 8 \% RH at $(75 \mu \mathrm{m})$ & 128.6 & 325 & 421.674 \\
\hline PMMA - 8 \% RH at $(25 \mu \mathrm{m})$ & 129.2 & 365.7 & 453.042 \\
\hline
\end{tabular}

\section{CONCLUSIONS:}

1. The thermo-physical properties of (PMMA- Ba) composite and (PMMA- $\mathrm{RH}$ ) composite increase with the rise of the weight fraction of $(\mathrm{Ba}$ and $\mathrm{RH})$ powders.

2. In DSC test, the value of glass transition temperature $(\mathrm{Tg})$ increases for all PMMA composites reinforced by either Bamboo powder or Rice Husk powder with increasing the weight fraction and decrease the particle size for both types of these powders when compared with pure PMMA.

3. The highest values of $(\mathrm{Tg})$ was obtained for (PMMA- $8 \% \mathrm{Ba}$ ) composite specimens at particle size (25 $\mu \mathrm{m})$.

\section{REFERENCES}

1. K.J. Anusavice, "Phillips' Science of Dental Materials", W. B. Saunders Co., St. Louis., $11^{\text {th }}$ ed., 145-737, (2008).

2. Stanley R. Sandler, Wolf Karo, Jo-Anne Bonesteel and Eli M. Pearce. "Polymer Synthesis and Characterization- A laboratory Manual", $1^{\text {st }}$ ed, Academic Press, New York, (1998)..

3. Belhaneche-Bensemra N., Bedda A., "Analysis of Structure Properties Relationship of PVC-PMMA Blends", Ann. Chim., Vol.26, No.3, PP.79-90, (2001).

4. Q.A. Hamad, "Study the Effect of Nano Ceramic Particles on Some Physical Properties of Acrylic Resins", Engineering and Technology Journal Vol.35, Part A, No.2, (2017)

5. Sihama I. Salih, Jawad K. Oleiwi and Qahtan Adnan Hamad, "Numerically and Theoretically Studying of the Upper Composite Complete Prosthetic Denture", Eng. \& Tech. Journal, Vol.33, Part (A), No.5, PP.10231037, (2015).

6. Jawad, K. Oleiwi, Farhad, M. Othman and Israa, F. Qhaze, "A study of Mechanical Properties of Poly Methyl Methacrylate Polymer Reinforced by Silica Particles (SiO2)", Engineering and Technology Journal, Vol.31, No.15, PP. 2925-2941, Part A, (2013).

7. A. Azlan et. al., "Mechanical and Thermal Properties of Hydroxyapatite Filled by Poly (Methyl Methacrylate) Composites," Proceedings of the Polymer Processing Society 24th Annual Meeting, University of Sains, Malaysia, (2008). 


\section{AL-QADISIYAH JOURNAL FOR ENGINEERING SCIENCES}

Vol.11, No.4

ISSN: $1998-4456$

8. Ayman E. Ellakwa, Mohamed A. Morsy, and Ali M. El-sheikh, "Effect of Aluminum Oxide Addition on the Flexural Strength and Thermal Diffusivity of Heat-Polymerized Acrylic Resin", Journal of Prosthodontics, Vol.17, PP.439-444, (2008).

9. Schajpal S. B. and Sood V. K., "Effect of Metal Fillers on Some Physical Properties of Acrylic Resins", Jour. Pros. Dent.; Vol. (61), PP.746-751, (1989).

10. O'Brien W J., "Dental materials and their selection", $3^{\text {rd }}$ ed. Chicago: Quintessence Int, PP.216-20, (2002).

11. Jawad K. Oleiwi, Sihama I. Salih and Hwazen S. Fadhil, "Water Absorption and Thermal Properties of PMMA Reinforced by Natural Fibers for Denture Applications", International Journal of Mechanical and Production Engineering Research and Development, Vol.8, Issue 3, Jun, PP.1105-1116, (2018).

12. Fu, Shao-Yun, and Yiu-Wing Mai., "Thermal conductivity of misaligned short-fiber-reinforced polymer composites", Journal of applied polymer science, Vol.88, No.6, PP.1497-1505, (2003).

13. P. Mummery, W. N. dos Santos, and A. Wallwork, "Thermal Diffusivity of Polymers by the Laser flash Technique", Polymer Testing, Vol.24, (2005).

14. Carola Esposito Corcione and Mariaenrica Frigione, "Characterization of Nanocomposites by Thermal Analysis Materials", Vol.5, PP.2960-2980, (2012).

15. Chow Wen Shyang, H. K. Tay, A. Azlan and Z. A. Mohd Ishak, "Mechanical and Thermal Properties of Hydroxyapatite Filled Poly (Methyl Methacrylate) Composites", Proceedings of the Polymer Processing Society $24^{\text {th }}$ Annual Meeting, PPS, University of Sains Malaysia, June, (2008). 